\title{
Livros e Leituras para Instrução Económica do Povo (1746-1820)
}

\author{
Francisco António Lourenço Vaz
}

[in Revista Portuguesa de História, Coimbra, Instituto de História Económica e Social, 20022003, t. II, p. 43-58]

Em anteriores trabalhos deparamo-nos, relativamente ao período em análise, com um conjunto de textos de cariz económico e dirigidos para as gentes simples ${ }^{1}$; entre eles sobressaem os catecismos de agricultura, corolários práticos e almanaques. Recentes pesquisas, no âmbito da História do Livro e da Leitura, levaram-nos a olhar para este acervo com interesse redobrado e a extrair da sua leitura novos elementos de análise e reflexão. É neste sentido que inscrevemos este trabalho. Com efeito, pretendemos fazer uma sistematização de alguns desses textos populares, e tentaremos responder a algumas questões: quais eram os objectivos dos autores? Que leituras eram recomendadas para instrução popular? Eram esses textos lidos pelo povo?

Os obstáculos a uma análise deste tipo foram já inventariados por Roger Chartier, a começar pela definição de povo, passando pela grande dificuldade em determinar as práticas de leitura e são também conhecidos os dilemas de uma história popular $^{2}$, quer porque os textos são, normalmente, produzidos por eclesiásticos, magistrados e outros membros das elites, que tem relativamente ao povo uma atitude de superioridade intelectual e até de distanciamento; quer porque se torna difícil, ou muitas vezes impossível, dada a falta de suporte documental, descrever o impacto dessas obras nas comunidades para que foram dirigidas. Com efeito, não foi feito em Portugal nenhum inquérito semelhante ao do Abade Gregório. Mesmo assim, pensamos que se pode traçar um quadro para nos apercebermos das ideais que animavam os autores que escreviam obras com um nítido objectivo de instruir o povo nas novas técnicas agrícolas e na indústria popular ${ }^{3}$.

A instrução do povo foi a bandeira das nações e do nacionalismo, sobretudo a partir de finais de setecentos, embora as suas raízes remontem à invenção da imprensa,

\footnotetext{
1 - VAZ 1998 e VAZ 2002.

2 - CHARTIER 1989; STRAUSS 1991.

3 - Excluímos desta análise os textos dirigidos para instrução dos comerciantes, assunto que abordamos em anterior trabalho.
} 
que tornou possível o proselitismo protestante e católico dos século XVI e seguintes ${ }^{4}$. Em Portugal, a primeira questão que nos parece pertinente, e que animava o debate entre os ilustrados portugueses, era a de saber se o povo devia ler. O debate, que irá prolongar-se até à segunda metade do século XIX, pode ser resumido com as conhecidas posições de Verney e Ribeiro Sanches. Enquanto para Luís António Verney, não havia qualquer dúvida sobre a necessidade e urgência de todo o povo, ou pelo menos todos os que usavam «camisa lavada», receberem uma instrução elementar, e portanto aprender a ler e escrever; já para Ribeiro Sanches, o filho do camponês e pastor devia continuar o oficio do pai, considerando a leitura um elemento perturbador, ou mesmo instigador para abandono do trabalho produtivo ${ }^{5}$. Podemos considerar que Verney era defensor de uma instrução popular, em todos os estratos e sem discriminação de sexo, enquanto Sanches persistia numa via elitista, defendendo um ensino para a nobreza e burguesia, mas considerando que nas aldeias não devia haver escolas e não se referindo praticamente a um ensino no feminino ${ }^{6}$.

As ideias de Luís Verney sobre a leitura das gentes do povo são ainda reveladoras de um duplo sentido: saber ler é útil para vida, mas é também divertido. Ora é este último aspecto que nos parece importante, relativamente às práticas de leitura, e que as palavras não desmentem:

Privam-se estes homens do maior divertimento que pode ter um homem quando está só, que é divertir-se com o seu o livro. Fazem-se escravos de todos os outros, pois, para ajustar contas, conservar correspondências, dependem dos mais. Fora de Portugal, vive-se de outra sorte: são tão raros os plebeus que não saibam escrever, como aqui os que sabem. O mochila, o carniceiro, o sapateiro, todos se divertem com os seus livros ${ }^{7}$.

Como documentam as palavras, a leitura é para o nosso autor uma prática solitária e divertida. Não devia Verney ignorar a leitura em voz alta e que era praticada tradicionalmente pelas gentes do povo, mas deixou vincado este individualismo, também ele sinal dos tempos que começavam a remeter a leitura para o silêncio.

\footnotetext{
4 - HERMET, 1996, p.79-84.

5 - « Depois, ensinar-lhe as quatro primeiras operações de Aritmética, que são necessárias em todos os usos da vida. Nisto há grande descuido em Portugal, achando-se muita gente, não digo ínfima, mas que veste camisa lavada, que não sabe ler, nem escrever». VERNEY 1746, p. 50.

«Que filho de Pastor quererá ter aquele ofício de seu pai se à idade de doze anos soubesse ler e escrever?». SANCHES 1760, p. 288.

6 - CARVALHO, 1986, p. 440.

7 - VERNEY 1746, p. 50.
} 
Retractam também o fosso que se estava a cavar entre Portugal e os restantes países europeus em matéria de literacia, facto que não cessaria de se agravar, e que nos colocaria na cauda do continente durante muitos anos, com reflexos indiscutíveis no desenvolvimento económico ${ }^{8}$.

Outra ideia que perpassa na obra de Verney, e que constitui também um modelo para os livros dirigidos ao povo, é que os livros sejam escritos em português e num estilo simples e acessível. Ora, os catecismos dirigidos ao povo, os pequenos catecismos, desde há muito que insistiam nesta simplicidade e clareza dos princípios, e por serem dirigidos ao povo deviam ser em língua nacional. Outro aspecto, que também contribui para tal vulgarização, foi sem dúvida o facto de o catecismo conjugar a oralidade com a escrita; ou seja, os catecismos tinham um discurso de fácil memorização e muitas vezes eram mais para serem ouvidos que lidos. Terão sido estes parâmetros pedagógicos que popularizaram o género e que o levou a domínios que extravasaram o religioso.

\section{Do catecismo religioso aos catecismos de agricultura}

O catecismo constitui um dos géneros de reconhecido sucesso editorial: primeiro sinónimo de instrução religiosa, na segunda metade de setecentos, e sobretudo com os acontecimentos revolucionários de 1789, invade outros campos de instrução: a política, a militar e a económica ${ }^{9}$. Por outro lado, nesta vulgarização do catecismo perpassa também uma ideia de instrução popular, que tem como fundamento a religião como geradora de bom costume e que era uma das ideias caras à ilustração católica, e particularmente a António Genovesi. Vejamos alguns textos onde ainda se parte desta concepção económica, nomeadamente, com uma não separação nítida entre moral e economia.

Relativamente à economia e actividades económicas, os primeiros manuais que encontrámos referem-se à agricultura, surgiram antes da Revolução Francesa, e tudo leva a crer num dos epicentros do proselitismo religioso e de alfabetização da Europa: a Alemanha. O economista português Francisco Solano Constâncio testemunha isso mesmo, quando refere numa das suas memórias a importância que se começou a atribuir

8 - HOBSBAWM 1979, p. 189 e CIPOLLA 1969, p 28-29. 
aos pequenos manuais, dirigidos aos camponeses para raciocinarem e conjugarem a teoria com a prática ${ }^{10}$.

Consultámos um desses catecismos de agricultura, escrito em francês, e redigido na Lorena, e portanto também com afinidades com a Alemanha, em que a conciliação da moral e da economia está bem vincada, como documenta o longo titulo ${ }^{11}$. A obra é em primeiro lugar dirigida às gentes do campo, a todos os que cultivam a terra, e assume um pendor pedagógico: instruir e ser útil. Contudo considera-se, também, útil para os habitantes da cidade; é isso que está bem vincado na advertência dirigida aos leitores, onde também se reconhece que aos ensinamentos podem ser úteis para os citadinos, nomeadamente, para cultivar flores e jardins ${ }^{12}$. Continuando nesta definição do público leitor da obra, o autor enumera os lavradores, os pastores, os vinhateiros e outras gentes que cultivam a terra ${ }^{13}$. Relativamente ao público leitor, há mais outros aspectos a salientar: o primeiro é que se sublinha o facto de o livro ser predominantemente dirigido aos jovens, porque os princípios da nova agricultura se inculcam melhor nas mentes jovens, pois são mais curiosos e com mais capacidade de aprender e, por outro lado, compete aos mais velhos transmitir a sua experiência aos jovens. Há portanto uma vontade expressa de passar para escrito dados empíricos, que podiam perder-se.

9 - Em França, são numerosos os exemplos de catecismos para uma instrução política; a começar pelos que pretendem inculcar os princípios do Direito Natural, ou os que pretendem ensinar os novos cânones revolucionários e particularmente o constitucionalismo.

10 - « Os sábios da Alemanha conhecendo quanto convinha fazer chegar à gente do campo a instrução sobre a economia rural, se ocuparam de diferentes obras elementares, escritas na língua do país ( ...) Um Catecismo de economia rural foi adoptado no Reino de Boémia em 1774 e introduzido em todas as Escolas de ler e escrever, para a mocidade do campo; no principio dele se encontra o pensamento seguinte: este Catecismo introduzirá nos camponeses o habito de raciocinar, no que pertence aos trabalhos da sua arte, e então se conhecerá quanto lhe convém unir a teoria com a pratica». CONSTANCIO 1818, p. 48-49.

${ }^{11}$ - Guy Hermet constata o facto de a alfabetização em França se iniciar primeiro nos territórios confinantes com a Alemanha, onde ecoou o proselitismo religioso protestante, e até uma emulação entre católicos e protestantes para aumentar o número de crentes. HERMET 1996, p. 73-74.

12 - «Cet ouvrage est composé pour les gens de la campagne, pour les hommes qui cultivent la terre: néanmois comme il renferme plusieurs choses qui peuvent être utiles à toutes les conditions de la vie, il est à souhaiter qu'il soit lu aussi dans les villes». Cathéchisme D'Agriculture 1773, p.3. Os ensinamentos para cuidar dos jardins, plantar flores etc. dificilmente teriam o interesse dos nossos agricultores. Assim não é de estranhar que a obra que consultamos tenha pertencido D. Thereza de Mello Breyner, quarta Condessa do Vimieiro, como atesta o ex-libris, que se encontra na contracapa.

13 - «C'est donc pour les laboureurs; les bergers, les vignerons et autres gens qui cultivent la terre, q'est fait cet livre». Ob. cit. p. 2. 
Definido o público alvo, segue-se a definição do objecto de instrução e do estilo literário. O fim moralista e moralizador, o bom coração, ou a conciliação do útil e do honesto, enunciado no início, não pode ser entendido como mero ornamento literário, mas como finalidade de um discurso económico fundamentado na ordem natural. A mesma ordem natural implica que o estilo usado se paute pela simplicidade: o conteúdo não é para sábios, nem se define pela complexidade, porque os ensinamentos são « simples e naturais» ${ }^{14}$.Um outro aspecto, é o facto de se contar com a colaboração dos curas para difundir esta obra junto dos camponeses, trata-se de outro parâmetro que teve grande aceitação por toda a Europa: atribuir aos párocos, detentores de autoridade moral, um papel interventivo na difusão de conhecimentos e técnicas. Papel que se torna imprescindível, dado que nem todos os camponeses sabem ler, ou não conhecem as obras que vão sendo publicadas ${ }^{15}$.

Em questões de método de exposição dos ensinamentos, convém salientar que a obra segue o género catecismo, ou seja um método dialógico, perguntas e respostas simples ( neste caso a criança pergunta e o pai responde), sobre os mais diversos trabalhos agrícolas ${ }^{16}$. Além do uso do diálogo, merece destaque uma inovação pedagógica, até porque rompe com a tradição seguida nos catecismos religiosos em França: o autor aconselha que as crianças não decorem este catecismo, porque o que é mais natural é compreender os princípios, já que eles são simples e naturais, e não fazer como os papagaios ${ }^{17}$. O conselho revela leitura das obra pedagógica de Rousseau, tal como outras recomendações, nomeadamente, para que não se use de castigos e que se aproveite a curiosidade natural das crianças.

Deve ter sido por inspiração deste género de catecismos que Diogo Mascarenhas Neto redigiu um Cathecismo de Agricultura, publicado nos Anais Sciencias das Artes $e$ das Letras, e no qual notamos uma importante evolução no género: a separação entre o normativo e cientifico, entre as máximas morais e religiosas e os ensinamentos da

14 - «... car ce qu'il est nécessaire de savoir pour la culture de la terre et pour le bien-être de l'homme est simple et naturel». Idem, p. 3

15 - Ob. cit. p. 20.

16 - Títulos das quatro partes: de l'agriculture en géneral; du labourage ou de la culture des champs; du labour des terres; de la culture de la vigne; des paturages et des troupeaux ; des jardins; des forets, de l'emploi du bois et de l'habitation du laboureur.

17 - Ob. cit. p. 19. Anote-se no seguinte regra enunciada num catecismo religioso francês: «Les Catechistes s'appliqueront à faire apprendre par coeur à tous les enfants le plus petit Catéchisme tout entier». POUGET 1707, p. 649. O catecismo para os confirmados insiste na leitura e releitura, mas insiste também na repetição: «Ainsi a force de lire, e d' entendre lire et repeter leur Cathéchisme ...». Idem, p. 650. 
«sciencia agronómica» ${ }^{18}$. É essa a principal mensagem que ressalta do prefácio em que Neto faz a revisão da bibliografia sobre ensino agrícola. Assim reconhece que «Os Elementos do respeitável Duhamel du Monceau», só podem ser úteis «para os mestres, e pessoas instruídas», que o catecismo de agricultura do Abade Bexon : «.. pela maior parte consta de máximas e exemplos de Moral» e no mesmo sentido vai a obra do Padre Frogger: Instruções de economia rural, para servirem nas escolas menores. Neto defende que as máximas de Moral já estão no catecismo religioso e que ao misturar o normativo com o científico está-se a instalar a confusão mas mentes e impedir os progressos em ambos $^{19}$. Feita esta separação, e relativamente a questões de método, ou exposição do ensino, o catecismo de Diogo Neto retém o método dialógico, não só « porque é o que mais se coaduna com aquela forma de ensino, mas também porque fatiga menos do que outro qualquer a atenção ainda ligeira da mocidade, e lhe grava mais profundamente na memória, pelas repetições, que nele são indispensáveis, as ideias, que convém adquirir» ${ }^{20}$.

No âmbito desta pesquisa, a obra de Mascarenhas Neto adquire, ainda, outros aspectos que convém realçar. O primeiro é que este catecismo é expressamente dirigido à mocidade e tem a ambição de ser adoptado nas escolas, em substituição de manuais que não são adequados. O segundo é que está em concordância com os princípios do ensino mútuo de que o autor era defensor, e de que os Anais tinham tratado logo no segundo tomo ${ }^{21}$. Se no primeiro caso parece orientar-se mais para um ensino cientifico e abandonando a ideia de raiz fisiocrática de instruir os camponeses; já no segundo ao insistir no ensino mútuo, parece orientar-se para o objectivo mais lato de instrução das camadas populares. Era sem dúvida no âmbito de uma ideologia liberal que se moviam as ideias de Neto a este propósito e, como tal, repletas de paradoxos e integradas no contexto do debate sobre a instrução popular, que continuava a preocupar as elites políticas e intelectuais em Portugal e no resto da Europa. Ora no âmbito desse debate, o

\footnotetext{
18 - NETO 1819, p.1.

19 - Ob. cit. p. 4

20 - Ob. cit.p.2.

${ }^{21}$ - «Agora oferecemos a primeira parte de um catecismo de agricultura ordenado de modo, que segundo o nosso parecer, combina com o método do ensino mútuo, e pode ser por meio dele ensinado nas escolas em lugar de outros livros, que nelas têm sido introduzidos, dos quais alguns estragam o desenvolvimento da razão na primeira idade, e não podem criar nela sentimentos acertados». NETO 1819, p. 2.
} 
ensino mútuo, pelas vantagens económicas era o que os liberais podiam oferecer como possível para o povo: barato e de baixa qualidade ${ }^{22}$

O catecismo propriamente dito utiliza o método dialógico, perguntas entre um mestre e discípulo, e divide-se em 73 lições, agrupadas em seis capítulo todos dedicados às plantas: substancias primitivas, germinação, vegetação, agentes da germinação e da vegetação, alimentos das plantas e os órgãos principais que servem á sua nutrição. $\mathrm{O}$ projecto de Neto seria continuar este catecismo, mas o que acabou por ficar foi apenas esta primeira parte. Aliás em publicação saída no número seguinte dos Anais, o autor aponta para outro tipo de publicação para o ensino agrícola, indiciando abandonar em definitivo o género catecismo, pelo menos no nome. Com efeito, seguindo os conselhos de Jovellanos, considera necessário duas obras: a primeira, « destinada a formar professores» e com uma linguagem científica; a segunda «somente para os Lavradores, a qual por essa causa até deveria ser indicada com o simples titulo de «Cartilha rural», e conter uma circunstanciada exposição dos trabalhos do campo, e do cultivo das plantas, escrita com estilo simples, e adequado à inteligência dos camponeses» ${ }^{23}$.

A evolução que notamos é que, começando por defender o catecismo de agricultura, Mascarenhas Neto agora fala em cartilha rural. Como já no catecismo defendera o fim das máximas morais e religiosas, era de prever que também no título os ensinamentos abandonassem o termo catecismo, que estava identificado com ensino religioso. Ora o ensino agrícola devia ser despido de considerações morais e religiosas e portanto também o título da obra deveria estar conforme com esse imperativo. $\mathrm{O}$ termo cartilha oferecia essa vantagem e teria também longa vida no que se refere ao ensino popular $^{24}$. Em termos de livros e leituras para o povo, pouco terá sido o impacto deste catecismo de agricultura. Ao contrário do que aconteceu na Europa central, entre nós os catecismos de agricultura ficaram-se pelas páginas dos Anais das Sciências, ou seja, não chegaram às mãos dos populares. Vejamos agora outros projectos e publicações para a instrução económica.

\footnotetext{
22 - «Aos pobres não era oferecido outro ensino além daquele que podiam dar a si próprios». HERMET1996, p.76.

23 - NETO 1819, p. 16.

${ }^{24}$ - Como comprova a Cartilha maternal de João de Deus.
} 


\section{Na indústria da seda e do linho}

As culturas da seda e do linho, duas indústrias que estavam em conexão com o trabalho agrícola e que eram objecto de inúmeras recomendações pelos teóricos da nova agricultura, já tinham uma longa tradição em Portugal ${ }^{25}$. Comecemos por ver alguns dos textos mais significativos que os nossos autores escreveram ou pensaram para instruir o povo nesses dois ramos importantes da economia nacional. Em primeiro lugar a sericultura, porque, apesar de alguns a encararem como «indústria de luxo», reunia um amplo consenso de governantes e economistas em finais de setecentos, em sintonia com uma mentalidade tardomercantilista ${ }^{26}$.

A primeira obra que encontrámos, com nítido pendor instrutivo, data contudo de seiscentos, e é da autoria de Rafael Bluteau ( 1638-1734): Instrução sobre a cultura das Amoreiras. Pegando nas palavras do autor, é um «livrinho», que teve pelo menos três edições: a primeira, de acordo com Inocêncio da Silva, saiu em 1679, a segunda foi inserta nas Prosas Portuguesas e a terceira, que foi a que consultámos, data de $1769^{27}$. A obra é dedicada ao Príncipe Regente, D. Pedro II, e pode ser encarada como um modelo para as dissertações e manuais que se seguiram sobre a indústria da seda. Não só porque o autor demonstra, em tom apologético, as excelências e vantagens da sericultura, mas também porque assume um sentido pedagógico bem vincado. Deste modo, a seda, qual eldorado, é uma «Maravilhosa Indústria para cada um dos Portugueses facilmente se fazer rico em pouco tempo». E basta ler a advertência feita ao leitor para nos apercebermos das grandes vantagens que se divisam na sericultura:

Abre os olhos Amigo Leitor, e adverte bem no tesouro, que agora as mãos te ocupam escondido neste pequeno volume (...). Depois de o leres com vagar, e sem paixão conhecerás, que nele te oferece a

\footnotetext{
25 - Encontramos interessantes referências a estas duas indústrias em Manuel Severim de Faria: «... pois em nenhuma parte da Europa se dá a seda, com tanta perfeição como em Portugal; como notam os Autores Italianos, e só falta ocuparem-se mais neste artifício». FARIA 1655, p. 26. E sobre o linho: «Não e menos importante o lavor do linho cânhamo, de que fazem as amarras, cordoalhas, e enxárcias, excedendo o nosso a todos os de Alemanha, de maneira que uma amarra de Portugal sustenta mais, que duas e três de Flandres». Idem p.25. Relativamente a estudos recentes, bem como transcrição de diversas fontes históricas, veja-se: SOUSA 2001 e 1999.

${ }^{26}$ - VAZ 2002, p. 402.

27 - SILVA 1863, p.45. BLUTEAU 1769. A edição consultada é de Coimbra, Imprensa da Universidade. Encontramos ainda referência a outras edições: entre 1769- 1771 a Mesa Censória autorizou a publicação destas instruções a dois livreiros de Lisboa: a Miguel Roiz e Miguel Monescal. Cf. BPE, Cod. CXXVIII/2-17, 1769-1771, fl. 65.
} 
fortuna um caminho entre todos o mais certo, e seguro para decentemente alcançares copiosas riquezas em poucos anos, sem gastos consideráveis, e com moderado, e divertido trabalho, que não dura mais de dois meses em cada ano ${ }^{28}$.

Anotemos, contudo e relativamente à leitura, que a recomendação é para que o livrinho seja lido «com vagar e sem paixão», o que parece ir no sentido de uma prática de leitura individual e de um discurso científico, ou seja, as instruções serão praticas, despidas de considerações subjectivas.

O tom apologético revela uma nítida intenção de convencer «todo o leitor» para cultivar amoreiras e criar bichos da seda e as razões básicas enunciadas são porque é uma industria lucrativa, útil e divertida. Acrescem a estas razões as benignas condições climáticas do país e, portanto, a sua principal finalidade é abrir os olhos aos portugueses que parecem estar adormecidos para esta maravilhosa indústria.

Quanto ao público leitor, as indicações de Rafael Bluteau não são precisas, menciona os «cavaleiros da Corte e pessoas do vulgo» ${ }^{29}$, o que indicia que a obra era dirigida tanto para nobreza como para o povo; mas mais à frente a propósito das pessoas que se podiam dedicar a sericultura insiste que é própria da nobreza, das damas e religiosas e até dos filósofos e teólogos ${ }^{30}$. Atendendo à época em que surge e pelas constantes referências à nobreza, pensamos que foi mais para convencer os «cavaleiros da Corte», avessos ao trabalho produtivo e mais vocacionados para o ócio, que Bluteau redigiu as instruções. Daí a insistência no carácter divertido, curioso e recreativo da sericultura. Nesse mesmo sentido pedagógico, os bichos da seda são comparados com eremitas ou anacoretas, ideias que pretendiam convencer damas da nobreza e religiosas, veiculando uma imagem de indústria digna de gente virtuosa ${ }^{31}$.

Após a «Prosa Económica», em que se justifica as vantagens e excelências da sericultura, já referidas, seguem-se as instruções. A matéria é agrupada em três partes tantas quantas as fases da industria: plantação de amoreiras, criação dos bichos e fiação da seda. Os ensinamentos são objectivos, claros e despidos de considerações, como se impunha. Trata-se, com efeito, de um enunciado das regras a seguir pelo produtor em

\footnotetext{
28 - BLUTEAU 1769, np.

29 - BLUTEAU 1769, p. 64.

30 - O sentido utilitário e divertido da indústria surge bem vincado, quando se fala para a nobreza e elites intelectuais: «O nascimento, criação, e vida dos bichos da seda encerram em si tão profundos mistérios, que não só por interesse, mas por recreação, e por curiosidade podem ocupar as pessoas mais virtuosas, as Religiosas, as Damas, os Filósofos, e mais doutos Teólogos do mundo». Ob. cit. 79.
} 
cada uma das fases, sem esquecer os pormenores ou recomendações importantes como, por exemplo, para plantar amoreiras em que se indicam os passos a seguir em cada uma das três modalidades: semente, mergulho e estaca ${ }^{32}$.

José António de Sá, Corregedor de Moncorvo, publicou diversos textos sobre sericultura, com destaque para as Dissertações Filosóficas e Políticas, donde extraiu, em 1787, uns Corollarios Praticos, dirigidos aos criadores dos bichos e fiandeiras de seda. Com eles procurava apresentar «as regras práticas, despidas de teoria, e capazes da intelecção dos Artistas, que, sem atenderem às razões físicas, e naturais, obram por uma simples rota, e mecanismo» ${ }^{33}$. Queria, deste modo, tornar a matéria acessível aos criadores e trabalhadores desta indústria, sem contudo esquecer os fundamentos científicos e técnicos mais recentes. Norteado pelos princípios da utilidade e do « amor à Pátria», o Corregedor queria também que este prospecto fosse distribuído gratuitamente pelas câmaras e concelhos e que mais tarde os "artistas" lhe fizessem chegar o produto da sua própria experiência ${ }^{34}$. Podemos considerar que se trata dum manual de instruções, com todos os passos a seguir pelos que pretendem dedicar-se à sericultura. Com efeito, agrupados em parágrafos enunciam-se de forma muito simples e clara os procedimentos, os corolários, nas duas principais fases. A primeira parte é dirigida aos criadores de bichos da seda e compreende todas as instruções necessárias a sua criação: como se devem preparar as sementes, como distinguir machos de fêmeas, como proceder durante o choco das sementes e qual o trato a dar aos bichos até a formação do casulo $^{35}$. A segunda parte, destinada às fiandeiras, apresenta os ensinamentos relativos à fiação da seda dos casulos; desde a morte dos bichos até ao tamanho das meadas, passando pelas indicações para construir as fornalhas para aquecer

\footnotetext{
31 - BLUTEAU 1769, p. 85.

32 - Assim por semente, tiradas das amoras: «.. semear em local fechado, defendido e abrigado», ou as sementes, ou mesmo as amoras inteiras. As amoras devem ser colocadas durante uma noite em água clara. Semear em Abril Maio; ou em Julho e Agosto. A época da Primavera é melhor. Deve escolher-se a lua no quarto crescente. Colocar as sementes distantes 4 pés umas das outras, transplantar as plantas quando estas atingirem altura de 6 pés e a grossura de um braço. Ob. cit. p. 96.

33 - SÁ 1787, p. 3.

34 - Idem.

35 - Em 55 parágrafos reúne toda uma serie de procedimentos que os criadores devem ter em consideração desde a separação dos casulos machos e fêmeas, até a alimentação dos vermes e do diagnóstico das doenças, passando pelos cuidados a ter em cada uma das fases do processo ou das metamorfoses. Desde a semente até à borboleta.
} 
a água onde se lançam os casulos, bem como as instruções para distinguir as 10 diferentes qualidades de casulos e cuidados a ter na fiação ${ }^{36}$.

A exposição dos ensinamentos difere dos catecismos de agricultura, porque abandona o método dialógico, de perguntas e respostas, mas continua a insistir na clareza e simplicidade das palavras. A matéria é dirigida a homens do campo, pequenos ou médios agricultores que viam a cultura de amoreiras, e criação de bichos da seda, como um importante complemento aos seus parcos rendimentos. José Sá conhecia bem essa realidade, nomeadamente, a rudeza das gentes das terras de Bragança e Moncorvo $^{37}$. Pena é que o autor não nos diga se o texto era para ser lido pelos grupos mencionados, ou se alguém mais instruído é que leria em voz alta, dado que a grande maioria dos camponeses e fiandeiras eram analfabetos. Tudo leva a crer que a hipótese mais plausível é que as instruções seriam lidas em voz alta. Dizemos isto, porque o próprio Corregedor fez uma sessão pública acerca da importância da cultura da seda, em que teve como parte importante a leitura na Câmara de Moncorvo das leis publicadas pelos governantes sobre a plantação de amoreiras ${ }^{38}$.

Encontrámos referências a outros textos com este mesmo sentido publicista e de instrução dos criadores de bichos da seda e plantadores de amoreiras. É o caso obra manuscrita de José Gonçalves Ramiro: Methodo novissimo para cultivar as Amoreiras, e Criar os Bichos da Seda ${ }^{39}$. Trata-se de um prospecto dirigido expressamente aos agricultores, para lhe dar instruções precisas sobre a criação dos bichos da seda e a cultura das amoreiras, nomeadamente, a qualidade das plantas, suas folhas e frutos, plantação, sítios favoráveis à cultura e poda. Instruções que o autor diz ter recolhido dos melhores tratados sobre a matéria e apresentadas, de acordo com as suas palavras, com pouca literatura, pois o compendio é para gente simples e escrito por quem não possui grande estilo literário ${ }^{40}$.

36 - SÁ 1787, p. 15.

37 - Cf. VAZ 2002, p.365.

38 - Como descreveu no prólogo das Dissertações Filosóficas, José António de Sá, quando chegou a Moncorvo, delineou um plano para incremento da cultivo de amoreiras, que incluiu uma parte pedagógica: em reunião camarária, e com presença da nobreza e povo, foram lidas as leis régias existentes sobre a matéria para assim se «persuadirem a este tão nobre, e lucroso trabalho». SÁ 1787, p. 6.

39 - BNL, Ms. 255 n. 39 s.d., p. 34. Inicia com o elogio a decisão régia de promover a cultura das Amoreiras e quer dar o seu contributo para esse fim.

40 - « ...talvez será do Real Agrado que os rasgos da minha mal aparada pena façam ver aos mesmos Lavradores os seus interesses, guiando-se pelas instruções de vários Autores, que tem tratado melhor desta matéria, cujas regras, em Compendio, me proponho fielmente transcrever Ob. cit., p. 2. 
Relativamente a cultura do linho, Frei José da Expectação, sócio da Sociedade Económica de Ponte de Lima, deixou expressas as suas ideias de apoio ao fomento da indústria popular, com uma obra intitulada: Tractado instrutivo da mais util cultura, fabrica, efeitos, e comércio dos linhos. Trata-se de um repertório sobre os conhecimentos e práticas para a cultura e fabrico do linho. Desde a sementeira até a fiação, passando por todas as técnicas necessárias ao preparo e as particularidades do « linho cânhamo», tudo é repertoriado de forma simples, atendendo aos destinatários da obra . Não esquecendo as grandes vantagens que o Estado pode retirar do progresso desta indústria, o monge beneditino conclui este manual com um optimismo e crença nas grandes potencialidades do trabalho produtivo e da sua importância para a felicidade pública e mesmo para a religião ${ }^{41}$.

\section{Instrução popular e luxo científico}

Os governantes, e particularmente D. Rodrigo de Sousa Coutinho, preocuparamse, também, em divulgar e fomentar a cultura da seda e do linho, junto das populações do interior. Foi neste sentido que o ministro mandou remeter ao Corregedor do Porto e a todos os Corregedores de Trás-os-Montes «vários exemplares das obras que se mandaram publicar sobre a cultura do linho cânhamo», para que os magistrados os distribuíssem pelos lavradores ${ }^{42}$. Mas iniciativas deste género não abundam, seja porque a conjuntura política era conturbada, seja porque as instituições vocacionadas para a difusão das luzes parecem alhear-se do problema que era o nosso atraso cultural, neste domínio da instrução popular. Um bom exemplo é a Academia das Ciências de Lisboa, que tendo nas palavras dos seus fundadores como grande finalidade a promoção das ciências e da indústria popular, talvez por excesso de ritual, de pompa e circunstância, um dos males herdados da mentalidade barroca, se transformou num « luxo científico». Embora tenhamos de reconhecer o radicalismo inerente na expressão utilizada por Borges Carneiro nas Cortes vintistas, não podemos também deixar de constatar que

\footnotetext{
${ }^{41}$ - BACL, Ms. 374 (2), s.d. fl. 15-63. O tratado, que foi enviado à Academia das Ciências, certamente para obter publicação, acabou por ficar manuscrito.

42 - ADB, Livro 27 Maço 7, 1799, fl. 288v-289. Trata-se de dois avisos, datados de Lisboa 10 de Junho de 1799, assinados por D. Rodrigo de Sousa Coutinho. O primeiro aviso é dirigido ao Corregedor de Bragança e o segundo ao Porto e neste se refere que se enviam «três exemplares de obras que tratam da mesma cultura; para q. vossa $S(a)$. os distribua pelos lavradores que se dispuserem a semelhantes e tão úteis tentativas..». Diz que os mesmos exemplares foram remetidos aos restantes corregedores da Província de Trás-os-Montes.
} 
efectivamente muitos dos projectos instrutivos dirigidos à Academia ficaram sem concretização.

Assim, o Tratado sobre a cultura do linho, de José da Expectação que, como salientámos era de grande utilidade para a divulgação e rentabilização desta indústria, ficou manuscrito e embora ainda persistisse uma circulação de textos manuscritos, não restam dúvidas que o suporte impresso tinha outro impacto quer geográfico, quer temporal. O mesmo aconteceu a um projecto que Avelar Brotero apresentou à Academia das Ciências para redigir três tratados: um sobre a criação de porcos, outro sobre o gado lanígero e um último sobre apicultura. Como demonstram os itens apresentados, pelo grande botânico, as matérias eram bem populares e o seu público alvo eram os criadores e produtores, que precisavam de instruções adequadas às novas técnicas e de acordo com conhecimentos científicos mais recentes ${ }^{43}$. O plano não teve o aval da Academia, e por isso ficamos só com os tópicos a desenvolver, e que nos demonstram a actualidade literária e grande interesse económico que as obras podiam ter entre os produtores portugueses. Com efeito, não se esquece Avelar Brotero de indicar a bibliografia para cada um dos ramos da economia rural; sendo referenciados o Sistema Natural de Lineu, Historia Natural de Buffon, Dicionário de Agricultura do Abade Rozier e Enciclopédia Metódica ${ }^{44}$.

A Academia fez orelhas moucas a estas propostas e continuava empenhada em fazer, com grande pompa e circunstância, e naturalmente com muitas discussões bizantinas pelo meio ${ }^{45}$, o grande Dicionário da Literatura Portuguesa, dando assim razão aqueles que consideram que entre nós o carácter literário da instrução foi sempre mais apoiado que o das ciências e técnicas, ou do que a instrução popular ${ }^{46}$. Os ilustres académicos estavam mais preocupados com o modo como se escrevia ou falava, se era usando os termos quinhentistas, ou actualizando as palavras, do que com o analfabetismo. Provavelmente, porque viviam em Lisboa e bem distantes do povo rude,

\footnotetext{
43 - BROTERO, s.d.

${ }^{44}$ - BROTERO ob. cit. fl. 267v.

45 - O deputado Borges Carneiro traduziu bem a situação numa discurso parlamentar em 1823, para impugnar a verba atribuída pelo orçamento e criticar o "luxo literário» da Academia: « Mas estar a Nação a gastar 4:800\$000 réis anuais para manter o prurido de escrever cousas que se não gastam nem dão para a despesa, para manter o luxo cientifico, e as vaidades dos sábios, nada disso». in VAZ 2002, p. 227.

46 - CARVALHO 1989, p. 580.
} 
com quem não se identificavam e até não compreendiam, ridicularizando os dialectos e regionalismos 47 .

Finalizemos esta análise com uma referência a Solano Constâncio, outro dos mentores dos Anais de Ciências e Letras, que se preocupou com a instrução popular, ao defender em diversos textos o ensino mútuo e ao postular mesmo a divulgação da Economia Política, recorrendo a um conhecido texto de Baptiste Say. Anotamos, mais uma vez o recurso ao género catecismo, no qual o redactor português via vantagens notórias:

A ideia do catecismo é feliz, porque as verdades desta ciência não devem ser conhecidas somente dos que fazem dela um estudo especial; é necessário, que elas penetrem todas as classes de uma nação, $e$ que se tornem populares, porque são destinadas a reformar as legislações, que se fundam em erros, e a assegurar os verdadeiros interesses da sociedade. Se o princípio da liberdade de comércio se não tivesse popularizado em Inglaterra, nunca o ministério inglês empreenderia a reforma, que tão corajosamente tentou (...). O catecismo de M. Say deve triunfar de todos os prejuízos vulgares, porque mostra a verdade debaixo da simples forma do bom senso ${ }^{48}$.

O género catecismo podia, assim, ser utilizado para levar a instrução da ciência económica aos populares, para acabar com preconceitos e prejuízos. O economista português destaca as capítulos, relativos às trocas, moeda, comércio estrangeiro, impostos e empréstimos públicos, porque «os exemplos, que o autor escolheu habilmente, facilitam a inteligência ao leitor, e dissipam a desconfiança, que muitas vezes ideias gerais inspiram aos espíritos pouco versados em abstracções» ${ }^{49}$.

Em jeito de conclusão, podemos dizer que o conjunto de textos para instrução económica obedeciam a um objectivo bem preciso. Para o povo, as elites intelectuais e políticas pensavam e ofereciam produtos de baixa qualidade e custo: manuais em estilo catequético e o ensino mútuo. Porque as elites continuavam o conhecido preconceito de Voltaire: o povo era estúpido, portanto, não era dado a abstracções, nem a grandes leituras. Preconceito que, partindo da afirmação da superioridade intelectual dos homens bem instruídos, os levava a procurar endoutrinar o povo, mais do que a aprender com o

\footnotetext{
47 - Bento Farinha, que também documenta o debate sobre o purismo da língua e a polémica do Dicionário da Academia, insurge-se contra os pedantes que criticam os dialectos regionais, mas se esforçam por usar francesismos. Cf. VAZ 1993, cap. V.

48 - CONSTANCIO 1819, p. 247.

49 - Idem, 249.
} 
povo, ou a olhar para os grupos populares como dotados de saber e cultura genuínas. Aspectos que em breve o romantismo realçaria.

\section{BIBLIOGRAFIA}

\section{Manuscritos}

Biblioteca Pública de Évora (BPE), Cod. CXXVIII/2-17, doc. n. ${ }^{\circ} 39$, Catalogo dos Livros, e Papeis que entraram a Despacho na Real Meza Censoria desde o dia 10 de Abril de 1769 ate 23 de Dezembro de 1771, fl. 65.

Biblioteca Nacional de Lisboa (BNL), Ms. 255 n. ${ }^{\circ}$ 39, doc. 23, José Gonçalves RAMIRO, Methodo novissimo para a cultivar as Amoreiras, e Criar os Bichos da Seda, sd, p. 34.

Biblioteca da Academia das Ciências de Lisboa (BACL), Ms 374 (2), Memorias Fizicas e economicas que não tiveram lugar nas Coleccoens da Academia, t. 2., José da EXPECTAÇÃO, Tractado instrutivo da mais util cultura, fabrica, efeitos, e comercio dos linhos., fl. 15-63.

BACL, Ms. 17 (23), Memorias Fizicas e economicas que não tiveram lugar nas Coleccoens da Academia, t. 1, nº 23, fl. 265- 276: Planos de tres tractados ou Memorias de economia Rural. $1^{o}$ - sobre a criação de porcos $2^{\circ}$ - Sobre o gado lanigero, $3^{\circ}$ - sobre as abelhas por Felix de Avellar Brotero

Arquivo Distrital de Bragança (ADB), Livros do Registo da Câmara de Bragança, Livro 27 Maço 7, 1775-1804, Registo de Dous Avizos de S. Magestade sobre a cultura do linho Cañamo, 1799, fl. 288v-289.

\section{IMPRESSOS:}

BLUTEAU, Rafael; Instrucçam sobre a Cultura das Amoreiras e Criação dos Bichos da Seda, Coimbra: Na Real Impressão da Universidade,1769.

CARVALHO, Romulo, História do Ensino em Portugal, Lisboa: Gulbenkian, 1986.

Cathéchisme D’Agriculture, ou Bibliothéque des Gens de la Campagne; Dans laquelle on enseigne par des procédes très-simples l'art de cultiver la terre, de la faire fructifier, e de rendre les hommes qui la cultivent meilleurs e plus hereux. On y a joint l'art de cultiver les fleurs e les jardins potagers, Paris: Chez Valade, 1773.

CHARTIER, A história cultural entre práticas e representações, Lisboa: Difel, 1989. 
CIPOLLA, Carlo, Literacy and Development, Harmondsworth: Peguin Books, 1969.

CONSTANCIO, Francisco Solano Constancio, Leituras e ensaios de Economia politica (1808-1842), Lisboa, Banco de Portugal (1808-1842), 1995.

CONSTANCIO; Francisco Solano, « Memória historica, e observações a respeito do ensino da Economia Rural», Annaes das Sciencias e das letras; por huma Sociedade de Portuguezes Residentes em Paris, t. 1, Paris A, Bobbée, 1818. pp. 38-79.

FARIA, Manuel Severim de (1655), Notícias de Portugal, introdução, actualização e notas de Francisco Vaz, Lisboa: Colibri, 2003.

HERMET, Guy; Histórioa das Nações e do Nacionalismo na Europa, Lisboa: Estampa. 1996.

HOBSBAWM, Eric, A Era das Revoluções, Lisboa: Presença, 1982.

NETO, Diogo Mascarenhas, «Análise do curso de agricultura de D. Augustin de Quinto», Annaes das Sciencias, das Artes e das Letras, Paris, A. Bobbée, tomo 6, 1819, pp. 3-28.

NETO, José Diogo Mascarenhas, «Cathecismo de agricultura», Annaes das Sciencias, das Artes e das Letras, Paris: A. Bobbée, 1819, t.3 , p. 1-80.

POUGET, A., Instructions Génerales en Forme de Cathechisme (...) Avec Deux Cathechismes abregés, a l'usage des Enfants, Paris: Chez Nicolas Simart, 1707.

SÁ, José António de, Dissertações Philosophico-Politicas sobre o tratado das sedas na Comarca de Moncorvo, Lisboa: Officina da Academia das Sciencias, 1787.

SÁ, José António, Corollarios Praticos extrahidos das Dissertações PhilosophicoPoliticas sobre o tratado das sedas na Comarca de Moncorvo, Lisboa: Officina da Academia das Sciencias, 1787.

SANCHES, António Nunes Ribeiro, Cartas sobre a Educação da Mocidade, in Obras, Coimbra: Universidade de Coimbra, 1959.

SOUSA, Fernando de, A indústria das Sedas em Trás-os-Montes (1835-1870), Lisboa: Edições Cosmos, 2001.

SOUSA, Fernando, «A reestruturação das sedas em Trás-os-Montes nos finais de setecentos», População e Sociedade, nº 5, 1999, p. 5-43.

STRAUSS, «The dilema of popular culture», Past and Present, 1991.

VAZ, Francisco, «O Catecismo no Discurso da Ilustração Portuguesa», Cultura Revista de História e Teoria das Ideias, Lisboa: Centro de História da Cultura, 1998, vol. X, p. 217-240. 
VAZ, Francisco, As Ideias Pedagógicas em Portugal nos fins do século XVIII - Bento José de Sousa Farinha, Tese de Mestrado apresentada a Universidade Nova de Lisboa, Lisboa: 1993.

VAZ, Francisco, Instrução e Economia. As Ideias Económicas no Discurso da Ilustração Portuguesa, Lisboa: Colibri, 2002.

VERNEY, Luís António ( 1746), Verdadeiro Método de Estudar, Lisboa: Sá da Costa, 1959, vol V. 